\title{
A Modelling Framework for Assessing Adaptive Management Options of Finnish Agrifood Systems to Climate Change
}

\author{
Heikki Sakari Lehtonen (Corresponding author) \\ Economic Research, MTT Agrifood Research Finland \\ Luutnantintie 13, 00410 Helsinki, Finland \\ Tel: 358-4073-4753 E-mail: heikki.lehtonen@mtt.fi \\ Reimund Paul Rötter \& Taru Irmeli Palosuo \\ Plant Production Research, MTT Agrifood Research Finland \\ Lönnrotinkatu 5, 50100 Mikkeli, Finland \\ E-mail: reimund.rotter@mtt.fi; taru.palosuo@mtt.fi \\ Tapio Juhani Salo \\ Plant Production Research, MTT Agrifood Research Finland \\ 31600 Jokioinen, Finland \\ E-mail: tapio.salo@mtt.fi \\ Janne Antero Helin \& Yulia Pavlova \\ Economic Research, MTT Agrifood Research Finland, Finland \\ E-mail: janne.helin@mtt.fi; yulia.pavlova@mtt.fi \\ Helena Maria Kahiluoto \\ Plant Production Research, MTT Agrifood Research Finland, Finland \\ E-mail: helena.kahiluoto@mtt.fi
}

We gratefully acknowledge the financial support to IAM-Tools project by strategic funds of MTT Agrifood Research Finland.

\begin{abstract}
Improved assessment methods for agriculture production systems are needed to identify the risks and opportunities related to global changes in climate, markets and policies, and the consequences of alternative options of coping with and mitigating the changes. This paper presents the AGRISIMU modelling framework developed for ex-ante assessment of alternative policy and management options meant to support farms and agrifood sector adapt to climate change, maintain biodiversity and reduce nutrient emissions under Finnish conditions. The modelling framework represents a novel approach to the integration of data and output from several existing models like a dynamic regional sector model of Finnish agriculture, a farm-level optimisation model, a dynamic crop growth simulation model and models describing the nutrient dynamics in agricultural systems and a hydrological rainfall-runoff model. The framework is particularly aimed for Nordic conditions and to serve as an assessment tool that considers multiple factor and scale interactions.
\end{abstract}

Keywords: Adaptation and mitigation options, Agrifood systems, Climate change, Integrated assessment, Modelling, Multiple scale interactions, Nutrient emissions, Scenarios

\section{Introduction}

Global environmental change, liberalisation of trade and market changes, new agro-technologies and changing consumer preferences and societal demands, among others, drive the continuous dynamics and changes of 
agricultural systems all over the world. Projections from global models of climate in Finland and in Northern latitudes in general indicate an acceleration of warming at rates greater than the global average and increased mean precipitation (Betts et al., 2009). The impacts of changes in global drivers as well as in active policies and management actions on food production, the environment and farmer's livelihood are not well understood. The extent of these effects will depend on the capacity of agrifood systems (AFS) to adapt which is determined by various natural and socio-economic factors. There is an apparent need for improved assessment methodology and tools considering multiple factor and scale interactions. It requires to conceptually and operationally link biophysical models with farming system and market models in order to increase insight in the complexity of interactions in agriculture, and support policy making (Van Ittersum et al., 2008).

Integrated assessment (IA) modelling is an emerging approach for facilitating public decision-making. We can observe several trends that underpin the importance and increasing demand for such Integrated Modelling of AFSs. These trends include, among others; a clear shift within the EU from "pure" agricultural policies towards sustainability enhancing policies, agricultural innovations (new agro-technologies and farming systems) have to increasingly satisfy multiple objectives and the instrument of policy impact assessment (ex ante assessments) has been firmly introduced to enhance the quality of policy formulation since 2003, at the EU level (EC, 2005).

These developments confirm the need for integrated and multi-scale approaches for ex ante assessments of the effects of policies and agricultural innovations in achieving sustainability objectives at the farm, regional and sector, and food system level. At the European level, to this end, the Integrated project SEAMLESS (www.seamless-ip.org) has been launched in 2004, in order to develop a tool-box for IA for EU-27 (the current EU with 27 member states) that can be applied across Europe to examine various agri-environmental problems at multiple scale (Van Ittersum et al., 2008). SEAMLESS has come up with a new software architecture for IA modelling (SEAMLESS-IF) and new generic component models (Ewert et al., 2009). However, it doesn't sufficiently address the specificities of Nordic conditions - neither in terms of important crop species (e.g. spring cereals like oats and barley), or specific agro-ecological conditions and their effects on soil-plant processes, nor in terms of socio-economic conditions.

Agricultural production in the North could benefit from the warming climate, if, at the same time adequate strategies are developed for AFS to cope with the higher risks imposed by increased climatic variability including higher frequency and severity of extreme events such as droughts and flooding. Most climate change projections show increasing length of growing season and precipitation in Northern Europe (Betts et al., 2009). This should increase crop yield potential and attainable yields, especially when taking the effect of enhanced $\mathrm{CO}_{2}$ concentration into account. At the same time, however, introduction of new crops and mild winter conditions will lead to invasion of new pests and diseases. The increase in winter temperatures will first lead to decreased length of snow cover and more frequent soil freezing and thawing cycles that will be problematic for overwintering crops. Rainy winter seasons without soil freezing will increase nutrient leaching and can destroy soil structure. All these changes in physical production conditions will have implications on composition and management of AFSs.

AGRISIMU modelling framework was developed particularly to cope with climate change related questions in Nordic conditions including multi-level environmental and market changes and their linkages within the AFSs. It gathers readily available and developing modelling tools as a research framework by covering the most relevant linkages between different levels and tools. Creating such framework and operationalising it as a numerical simulation tool is our ambitious target. However we believe that many relevant climate change related linkages between the different levels of food system can already be modelled, utilising existing data or anticipated research results. We can utilise many existing research tools and studies capable of capturing core elements of climate change in the Nordic conditions.

The major goal of the current paper is to present the overall approach and concepts of a novel modelling framework, AGRISIMU, for integrated assessment of AFS in Finland. The framework is particularly aimed at ex ante assessment of technologies and policies available for climate change mitigation, adaption and reducing nutrient emissions to ground and surface waters from agriculture in Nordic conditions.

\section{Agricultural research and tools for Integrated Assessment}

The burning questions regarding the relationship of agricultural systems, sustainability and society, can only be addressed using a systems perspective. Agro-ecosystems are socio-ecological systems, which implies that agricultural research cannot alone provide a consistent view on how agriculture can contribute to sustainable rural development and how to make AFS more sustainable, but provides only limited understanding of agrifood system behaviour. Numerous examples exist illustrating that agro-ecological or agro-economic principles are not 
adopted due to socio-cultural constraints or their relatively small role in the constraints that farmers face. On the other hand, judicious IA of agricultural systems is not possible without sound agricultural knowledge. The latter is the basis for explaining agrifood systems behaviour, interactions with the environment and identification of promising activities that meet multiple objectives. To assess the performance and contribution of AFS to sustainable development, process-based knowledge is indispensable. According to Bland (1999), a key challenge for agricultural research is to identify to what extent agronomic knowledge should be synthesized for integration in multi-scale agro-ecosystems analyses. During 2008 the IAM-Tools project was launched to enable researchers in and outside Agrifood Research Finland (MTT) to meet the increasing demand for such integrated studies.

The major integration levels are the crop/cropping system, farming system and national level. At the cropping system level, information on natural and socio-economic resources needs to be integrated with agronomic information; at the farm level, in addition, costs, prices and farmers' decision behaviour needs to be integrated with biophysical information. At the national level policy views are a major addition. Most of the methods to deliver agronomic knowledge for integrated studies are model-based. One of these model-based approaches is dynamic crop growth or cropping systems simulation models (Van Ittersum et al., 2003). The other group delivering agricultural input-output matrices or coefficients as input to bio-economic models (Rötter et al., 2005) are the so-called technical coefficient generators (Ponsioen et al., 2006). Some of the input-output relations are usually generated by dynamic simulation models. Bio-economic models are either used to study farm household decisions and performance (e.g. farm household models) or regional land use decisions and optimization of land and resource use for set of (rural development) objectives (Rötter et al., 2005). For taking both macro-economic policies, and environmental policies (e.g. nutrient and climate change policies) into account at national, continental or global level, specific IA tools have been developed or linked such as IMAGE (IMAGE team, 2001) and GTAP (Van Tongeren et al., 2001). However, from the literature it is evident that the use of these research tools for (multi-scale) integrated assessment of policies and agro-technologies is very restricted in practice; those approaches applied are still often disciplinary and directed at a single decision level and spatial scale, and are thus not suitable to make the multi-scale impacts and interactions transparent (Van Ittersum et al., 2004; 2008). Especially the gap between micro-level (field and farm) and macro-level (region and sector) analysis has hardly been bridged - with only a few methods designed for multi-scale assessments (Laborte et al., 2007).

\section{Modelling framework}

\subsection{The basis and methodology for developing the envisaged modelling framework}

The problem to be addressed can be summarized as follows: both biophysical (climate change) and socio-economic (policy and market) drivers will lead to changes in agricultural production and land use. These changes will in turn have impacts on environmental quality, especially on greenhouse gas (GHG) emissions, soil carbon balance, nutrient loading and biodiversity. Currently, the main interventions to preserve environmental quality are through adaptive management at farm level. However, these short-term tactical responses need to be linked to long-term strategic options for whole regions, such as (re-)design of agricultural systems, supported by agricultural, environmental and rural development policies implemented at different decision levels.

The framework that is being developed for ex ante assessment of alternative policy and adaptive management options from field to national level is called AGRISIMU (AGRIfood systems SIMUlation) (Fig.1).

The starting point in the AGRISIMU modelling framework (Fig 1.) is a set of alternative scenarios of the main driving factors of global change, that are down-scaled to construct regional scenarios of the major factors likely to influence agro-ecosystems. While the analytical steps connect different management and decision levels from field to supra-national, most of the tools being developed and interlinked focus on the field, farm and regional levels. AGRISIMU is being build by revising existing and designing new models, interlinking the models or their results at the farm (in SAMA) and regional/catchment level (DREMFIA) and integrating the information in a GIS environment. Economic models SAMA and DREMFIA include a certain level of biophysical detail facilitating a preliminary integration. Inputs and outputs of the models currently applied within the AGRISIMU framework are listed in Table 1.

The extrapolation of the point estimates of soil-plant models to higher aggregation levels (farm and watershed levels) is realized through linkage of the point models with agro-ecological databases in a GIS environment. This will allow various upscaling procedures, both data input aggregation for regional models or model output interpolation using representative sites or calculations units (e.g. derived agro-ecological units) based on quantitative land evaluation. 


\subsection{Field and regional level soil and crop modelling}

Soil-plant models within the framework are used to assess the impacts of climate variability and change, and effects of changes in management practices at field or cropping system level on production and soil-plant processes. In addition to yield estimates, also nutrient leaching and GHG emissions from fields are estimated with these tools. A dynamic crop growth simulation model within the AGRISIMU framework is used to estimate yields and growth indicators under various production conditions varying in terms of weather, soil, crop or cultivar properties and management. Crop models work typically on field level. Currently, the model applied for the purpose is WOFOST (Boogaard, et al, 1998) which belongs to the family of models developed in Wageningen by the School of C.T. de Wit (van Ittersum, et al, 2003). The dynamic crop growth simulation model simulates growth and yield formation of annual field crops, their water balance and nutrient requirements based on eco-physiological principles and using a hierarchical approach to simulating crop growth in three different production situations: potential, water-limited and nutrient-limited production. WOFOST has been implemented for the EU on a 50 x $50 \mathrm{~km}$ grid during the 1990s (Supit et al., 1994). Recently it has been calibrated for some modern rapeseed and barley cultivars growing in Finnish conditions. The model can now be run on a (10 x $10 \mathrm{~km}$ grid-basis) for the whole of Finland, but regional yield estimation (Moen et al., 1994) still requires further evaluation. In the framework of a COST action 734 (www.cost734.eu) we are also evaluating the capabilities of different crop models for the purpose of finding an optimal tool for decision support in terms of adaptive management and climate change. Particularly, it would be important to be able to deal with the specialities of Nordic conditions, such as long day lengths, overwintering and peat soils.

While with WOFOST we can simulate the impacts on crop phenology, biomass, yield, water use and other water balance components, it is not capable to sufficiently assess the impacts and interactions of the water balance with $\mathrm{N}$, $\mathrm{P}$ leaching and $\mathrm{C}$ dynamics in the soil. For $\mathrm{N}$ and $\mathrm{P}$ dynamics we use ICECREAM (Yli-Halla et al. 2005) and Coup Model (Jansson and Karlberg, 2004). These are one-dimensional simulation models representing water and heat dynamics in a layered soil profile covered with vegetation. ICECREAM includes the effect of agricultural practices on both nitrogen and phosphorus transport whereas Coup Model considers especially different parts of nitrogen cycle and transport. In Finland, COUP model (e.g. Salo 1996; Rankinen et al. 2007) and ICECREAM (e.g. Granlund et al. 2007) have been used for different applications. We intend to use these models within AGRISIMU to estimate soil water balances and turnover of both nitrogen and phosphorus in agricultural soils. The effect of changes in soil structure can be modelled by changing soil physical characteristics. Furthermore carbon cycle and change in soil carbon stocks will be simulated. For the watershed level, INCA-N model (Wade et al., 2002) is used to simulate $\mathrm{N}$ leaching, and WSFS-P (Huttunen et al., 2007) for simulating phosphorus transport

In support of this, we also embarked on generation of comprehensive data sets (crop, weather, soil, topography, management practices) for model evaluation and development; that includes some new experiments designed for calibrating and validating the soil-plant models for specific conditions. Dynamic crop growth simulation models require data from the field and agronomic experiments to parameterize their descriptions of soils and crops. Soil parameters are essential for modelling soil hydrology and water balance, and nutrient balance. Water balance affects both crop growth and nutrient leaching. Crop parameters determine the development and growth rates and dry matter allocation according to crop (cultivar) characteristics and the weather conditions. There are some available datasets (e.g. soil database of COUP) or pedotransfer-functions (functions to calculate soil physical characteristics from soil particle distribution) in order to characterise soils according to the available soil information. But we still need to integrate the existing soil database, available soil physical measurements, database of COUP and pedotransfer-functions. The main result of the work will be average values with standard deviation for Finnish soil types.

For the Finnish agricultural soils an important factor to be considered is how to manage the huge soil carbon stock of the organic soils. There are about 300000 ha of organic and mull soils in agricultural use. In the national GHG inventories, the emissions from organic soils are assessed applying empirical emission factors (Lapvetelainen, et al, 2007), which offers a straightforward method for assessing the emissions under current conditions. For scenario analysis, however, a mechanistic, process-based approach covering the most important causal relationships between the driving factors and processes may be more relevant and therefore the applicability of such models under AGRISIMU still needs to be further studied.

\subsection{Farm level modelling}

Modelling agricultural systems at the farm level depicts the system at a level where most of the farming decisions are taken. Hence, the farm level is well suited for understanding how changing production conditions 
will affect the production system. The need to account for heterogeneity of production systems has led to a multitude of farm level modelling frameworks and applications (Hazell \& Norton 1986, Balmann 1997, Chavas 1994, Janssen \& Van Ittersum 2007). Most importantly, farm level models to be employed in our analysis should create a link between farm level costs and benefits of climate change adaptation, i.e. take into account relations between farm activities in changed conditions. For example, climate change will bring changes into the Nordic production conditions and also possibilities for new cultivars and threats of pest invasions. Farm level optimisation can be used as a valuable tool to provide a view on how farm resources (land, labour, machinery) and variable factors of production (nitrogen and phosphorous fertilisation, feed use of different animals affecting yields and nutrient leaching) should be utilised on profit or utility maximising farms in these changed conditions with adapted agronomic practices.

It is important that the farm level model employed is capable of analysing farm level production decisions for a number of interrelated farm activities in terms of variables and dimensions relevant to the climate change. The Static Agent Model of Agriculture (SAMA) is a Finnish example of stylised multi-dimensional farm models, which optimise the use of farm land, nitrogen and phosphorous fertilisation of each crop, derive distances to field plots from GIS based systems, optimise feeding of dairy cattle (the dominant form of animal husbandry in Finland) using a detailed description of how animals utilise feedstuffs in their different combinations, and calculate a proxy (based on 10 years of weather data) for nutrient leaching from field plots, taking into account different tillage (e.g. Helin et. al. 2006, Helin 2009). Thereby SAMA integrates water quality protection and other emission reduction measures to a profit-maximising farm model. Hence the SAMA model, providing a profit maximising use of individual field plots, fertilisation and feedstuffs, can show how farms respond to different climate conditions and market scenarios. This information can be utilised in sector level analysis where a smaller number of farm level decisions can be accounted for.

SAMA model has also been expanded to a catchment scale for more refined integrated analysis of nutrient leaching Since SAMA model includes individual field plots and their sizes, soil types and slopes, its results as land use, tillage and fertilisation variables can be included directly to catchment scale nutrient models such as INCA-N which includes non-agricultural nutrient sources as well and can be evaluated with the observed pattern of daily nutrient concentrations in watercourses.

Applying farm level bio-economic models, such as SAMA, requires detailed input information from field level as well as information on production cost structures of different activities. Soil and crop modelling provide a source for the field level information. The required information on the current production organisation is provided by farm level databases and studies. The numerical calculation from crop level cultivation requirements in different climate scenarios can be done by calculation procedures similar to those applied in TechnoGIN (Ponsioen et al. 2006). The main importance of such calculations is to define the necessary input use structure for feasible cultivation of specific crops (cultivars) in specific conditions. Recommendations for cultivation practices for new cultivars are produced regularly by agricultural research and extension organisations. However the calculation of changed input requirements in the case of longer growing season, changed precipitation patterns and new cultivars, relevant for the climate change impacts in Nordic conditions including high irradiation levels during the early growing season, under various scenarios is more demanding. In that we rely and expect important insights from simulations using process-based soil-plant models.

In practice, defining optimal farm activity consistent with the best knowledge of plant and animal physiology together with the economic and environmental information is challenging. The number of decision variables and space grows rapidly especially when the relationships between inputs and outputs are taken into account, e.g. crop yield response to fertilizer application, impacts of changing feeding on milk yields and animal growth. In the current SAMA version, for example, the labour limitations and more complicated utility functions are excluded. An additional issue affecting the reliability of the optimisation results done for larger set of options to consider the effects of environmental, price or policy changes is that in practise the farmers tend to follow quite fixed rotations and input levels.

\subsection{Sector level modelling}

\subsubsection{Building blocks}

Sector level economic modelling at multi-regional national markets is an appropriate approach to consistent upscaling the crop and farm level impacts and adjustments. The sector level modelling with demand and foreign trade specifications is also an important integrating tool between animal and crop production at the level of regional and national production and land use. 
The dynamic regional sector model of Finnish agriculture (DREMFIA) is a dynamic recursive model simulating the development of the agricultural investments and markets on national scale and its 18 regions at annual time steps from 1995 up to 2020 and thereafter at ten year time steps at 2030, 2040 and 2050. The underlying hypothesis in the model is profit maximising behaviour of producers and utility maximising behaviour of consumers under competitive markets. According to microeconomic theory, this leads to welfare maximising behaviour and equilibrium market prices which are equal to marginal cost of production on competitive markets. Each region specialises in agricultural products that are of highest relative profitability, taking into account profitability of production in other regions and consumer demand. Total use of different production resources, including farmland, on different regions are utilised optimally in order to maximise sectoral welfare, taking into account differences in resource quality, technology, costs of production inputs and transportation costs (spatial price equilibrium; Takayama and Judge 1971, Hazell \& Norton 1986, Cox \& Chavas 2001).

DREMFIA (Lehtonen 2001) consists of two main parts: (1) a technology diffusion model which determines investments in different production technologies in different regions; and (2) an optimization routine which simulates regional production and national level annual price changes (supply and demand reactions) by maximizing producer and consumer surplus subject to regional product balance and resource (land and capital) constraints (Fig. 2). The parts (1 and 2) interact so that prices from the market simulation and optimisation model enter the technology diffusion model representing sector level investments in each region, and changes in animal production capacities of different techniques enter the market model in the following year. The production will gradually reach a long-term equilibrium or steady-state if no further changes in policy, technology or economic environment take place. For years 2030, 2040 and 2050 the model outcome represents a long run equilibrium where also fixed production resources, such as machinery and buildings, have adjusted to changed economic conditions and comparative advantage of regions. Technical change and investments, which imply evolution of farm size distribution and production capital in regions, are modelled as a process of technology diffusion as described by Soete \& Turner (1984). Production activities include number of different animals, hectares under crops and set-aside, feed diet, chemical and manure fertiliser use and the resulting crop yield level.

In the current conditions relatively low crop yields together with timeliness costs (short growing season with short sowing and harvesting periods) and unfavourable topography restrict gains of specialisation and economies of scale. Small and spatially fragmented field plots producing low yields increase farmers' working time and timeliness costs and imply inefficient use of capital on farms. However, if climate change, after appropriate adaptation, lead to higher yields and longer growing and peak working periods, farms and regions can increase their production, concentrate the production on most feasible areas and field plots (due to higher yields), and still cut labour and machinery costs. Taking into account higher yields and necessary changes in inputs, SAMA model can show resulting production optimisation at individual farms and catchments, while DREMFIA can show likely changes in regional production specialisation, national supply and prices, given EU (global) level price scenarios. Regional shifts of production may provide significant economic gains since production conditions vary a lot inside Finland.

There are 18 different production regions in DREMFIA, including 3 small catchment areas, of size $4-6000$ hectares, which match exactly the spatial aggregation of the bio-physical nutrient leaching models INCA-N or ICECREAM. This allows a regionally disaggregated description of policy measures and production technology and consistent linking to catchment scale nutrient leaching models with more biophysical detail (soil type, slope). Hence DREMFIA calculates how comparative advantage and production of individual catchments change with respect to other regions in different climate change and market scenarios, but unlike SAMA, it is unable to take into account the full spectrum of soil types and slopes or distances to watercourses. Concerning GHG emissions and possible climate policies, organic soils are separated from other soils in DREMFIA. Depending on selected policy to be analysed organic soils can be excluded from cultivation completely or they can be used only as grasslands. These options can be easily modelled in an optimisation model with explicit resource constraints. The share of organic soils of all farmland varies between $2-29 \%$ in different regions.

\subsubsection{Regional risk specifications}

Ignoring risk-averse behaviour in farm planning models often leads to results that bear little relation to the decisions farmer actually makes (Just, 2003; Hazell \& Norton, 1986). Risk aversion behaviour of farmers as well as changing patterns of crop and revenue risks is increasingly relevant in a changing climate. We adopted the mean-variance analysis with dynamic recursive sector model to explicitly include crop risks into estimates of land use changes in Finland (Lehtonen \& Kujala 2007). In classical mean-variance-model we maximize the utility function with positive risk aversion coefficient. In the optimum, the utility gained from the additional unit of activity equals with marginal costs. Typically, expanding the most profitable activities produces additional 
income uncertainty and costs determined by the risk aversion parameter subject to calibration in ex post simulation.

The variance-covariance matrixes of the crop contribution margins are calculated using data from 1995-2008 for the 18 regions in the DREMFIA model. The calculation of matrices shows that wheat, rye, malt barley and oilseeds have higher own variances than barley, oats and mixed grain mainly cultivated for feed use. The (co)variances of wheat, rye, malt barley and oilseeds further grow towards the north (Lehtonen \& Kujala 2007). The risk specification provides an endogenous explanation for the fact that some crops are not only cultivated in southern most favourable regions but also in few other regions as well.

Simple expansion of risk based on observed covariance matrices may produce misleading results. Dynamic, process-based crop growth simulation models (Van Ittersum et al., 2003), such as APES, DAISY, DSSAT, FASSET or WOFOST, to name a few, and their new versions tailored for climate change simulations could serve to create simulated realisations of crop yields and hence covariance matrices under different climate change scenarios. The new model version of WOFOST (Boogard et. al. 1998), evaluated for various crops under Finnish conditions, was recently applied successfully in combination with a weather generator to produce synthetic yield series (for up to 200 years), taking systematic changes in future climate, both changes in means (temperature, precipitation) and in climatic variability into account (Rötter et al., 2009). Automatization of data input generation and model runs have made such exercises feasible, even for entire Finland. The risk specification included in DREMFIA provides a major model link with simulations on crop growth and yield under alternative climate change scenarios.

\subsection{Integration using climate change mitigation as an example}

An example of the AGRISIMU application is an assessment of potential mitigation measures to reduce the greenhouse gas emissions from Finnish agriculture and to increase carbon sequestration of agricultural soils. GHG emissions originating from agriculture are 17\% of the total GHG emissions of Finland and they need to be reduced by $16 \%$ already by 2020 (Regina et. al. 2009). It is, however, challenging to find effective and sustainable measures, as there are complex interlinkages among the emission sources within the agricultural systems. To be able to cover those interlinkages and analyse the trade-offs, a modelling approach like AGRISIMU is needed for the analysis. In the following we indicate which model components of the AGRISIMU framework are used for each question.

Management of organic soils has significant potential in agricultural GHG abatement (Regina et. al. 2009). However, management changes on organic soils have implications for the management and emissions from non-organic soils. There is a need to specify crop and fertiliser choices, crop yields and overall farm management changes implied by restrictions on the use of organic soils such as "organic soils for grasslands only". For example, the spreading of manure is more expensive on grasslands than on lands to be ploughed for cereals - the overall costs of this can be calculated in SAMA farm level optimisation model. The cease of cereals cultivation on organic soils and/or the spreading of manure on grasslands (bovine animal farm case) may also change the purchase of fertilisers on the farm (Fig. 2: SAMA model). The purchase of fertilisers may also decrease if clover-grass is taken into cultivation, implying some other costs due to possible extensification of land use and changed crop rotation. The overall costs and benefits together with optimised land use is calculated in SAMA and DREMFIA models. Clover-grass option may also reduce the amount of purchased fertilisers and reduce $\mathrm{N}_{2} \mathrm{O}$ emissions from soils and nutrient leaching as well. The effect on purchased fertilisers can be analysed on farm and sector level, taking into account the opportunity costs of land in alternative use.

Within the assessment, greenhouse gas emissions (methane $\left(\mathrm{CH}_{4}\right)$ and nitrous oxide $\left(\mathrm{N}_{2} \mathrm{O}\right)$ as well as changes in the carbon stocks of agricultural soils) of different mitigations scenarios for the selected period can be estimated by combining the outputs from several soil-plant models (WOFOST, COUP and ICECREAM). Then field and farm level models (e.g. COUP and SAMA.) are applied to get the input information and parameters needed in regional level analysis. In SAMA, the use of field parcels of different characteristics is optimised and resulting changes in GHG emissions and their mitigations costs at the farm or small catchment level can be calculated directly. To be able to define the scenarios and information required at the sector level analysis of agriculture (DREMFIA), the technical requirements (inputs) of the selected mitigation measures and their costs and benefits at the farm level need to be defined. This is not straightforward, since farm level assessment should reflect the real decision making problem of the farmers as exactly as possible and not be based on options farmers consider unrealistic or too risky due to high costs, poor feed quality, hygienic reasons, weed problems etc. For example, in the context of restricting cereals cultivation on organic soils, avoiding hygienic risks of manure application on grasslands may require the use of more expensive equipment. This extra cost can be easily included in the 
SAMA and DREMFIA models. However, certain mitigation options may require changes in the entire production organization on certain types of farms. For this reason, some necessary input use calculation may need to be done outside the individual model components, and then feed the specific information into the models.

The agricultural sector model DREMFIA calculates how certain farm level adjustments lead to changes in production and prices of agricultural products in different regions (having different shares of organic lands). For example, decreasing production of cereals, milk, beef and pork on organic soils may be compensated by increasing production volumes on nonorganic soils (Lehtonen 2006). The results from DREMFIA, i.e. development of land use, numbers of different animals and chemical and manure fertilisation for each crop up to 2050, will in turn be fed to the calculation models used for making the GHG inventory for the Climate Convention (one for $\mathrm{CH}_{4}$ and $\mathrm{N}_{2} \mathrm{O}$ and one for soil carbon), as well as to nutrient leaching models ICECREAM and INCA. The aggregate level emission mitigation potentials and costs of the selected mitigation measures will then be estimated.

This example of the IAM provides information for farmers on how GHG mitigation measures influence production and economy on their farms. The results can also be utilized to support decision-making on Finland's future climate policy after the commitment period of the Kyoto Protocol. Integrated information on the efficiency of different measures will ease their adoption and eventually result in more climate-friendly agricultural practices, which may also have important implications and possible synergies to nutrient leaching abatement from agriculture. GHG mitigation costs and their sensitivity to agricultural product and input prices can be calculated, facilitating estimates of the required compensations and incentives through agri-environmental policies necessary to motivate farmers in GHG abatement.

\section{Discussion and conclusions}

\subsection{Discussion}

Upscaling of the impacts of climate change induced changes in soil and crop level processes is primarily done to fit the resolution of input required for farm and sector level economic models. Some biophysical detail exist already in farm and sector level economic models, but certain issues, such as crop response to changed nitrogen fertilisation, especially in the case of radically changed crop growing conditions (climate) and new cultivars, can only be included in the economic models if certain crop response functions do exist. In the case of new cultivars, for example, not only nitrogen response function is needed but also the use of other inputs, such as crop protection, tillage method and necessary machinery (capital) equipment at the farm level must be specified. This requires agronomic understanding, for instance, which particular inputs are needed, and at which cost relative to the traditional farm production organisation. It must be realised that existing farm level models rely much on observed, widely spread farm level production organisation and use of inputs derived from aggregated databases. Elsewhere, knowledge about future alternative production activities has been formalized in input-output coefficient generators (Ponsioen et al. 2006; Pathak \& Wassmann, 2007). Development of such tools for Finnish conditions should receive priority.

At the sector level the relevant economic adjustment mechanisms of the farm level must be represented, i.e. the farm level adjustments must be at least approximated by the same kind of response functions and input use specifications in a multi-regional sector model. Also the possibilities for new types of production organisation, studied at the farm level, can be taken into account in the sector model since the input aggregations and the shape of crop response functions are very similar in SAMA and DREMFIA. While the sector model economises the spatial structure of production in changed productivity, input use, price and policy conditions, the most important region specific possibilities and restrictions need to be taken into account. For example, soil types at regional scale play a role. Soil characteristics, such as mineralisation of nitrogen in organic soils may be relevant in terms of necessary nitrogen fertilisation and crops cultivars' ability to utilise nutrient during a growing season. Databases with reliable, systematically constructed and evaluated information is a necessary prerequisite for modelling long-term impacts and adjustments of agriculture.

Regional production structures may change in response to economic and climate changes. Global and EU level market scenarios and biophysical changes affecting crop productivity, use of inputs and possibilities of adjustments in regions, are summed up via comparative advantage and balancing supply and demand in a way that utility of consumers and profits of producers is maximised. This theoretical standpoint brings our analysis into long-term trajectories of national and regional structure and production of agriculture. Changes in consumer preferences and demand (for meat, for example) may play a significant role. AGRISIMU framework can be used in studying socio-economic scenarios, including EU or global commodity and input price changes and shifts in 
food demand, in combination with changes in crop growing conditions. In this, changed uncertainty of farm revenues, induced by changed variance of yields and prices, can be considered consistently as implicit cost for farmers.

Overall, the AGRISIMU framework can serve as a major platform in upscaling and integrating crop, region, cultivation method and market level options into consistent storylines of agriculture. On that basis we can analyse different adaptive options and show to what extent they lead to achievement of different (multiple) objectives of agriculture as well as their trade-offs. For example, very recently the importance of maintaining or even increasing agricultural production potential and food security has been emphasised, together with the compelling needs to cut nutrient leaching from agriculture to Baltic Sea, as well as commitments to cut agricultural GHGs substantially. At the same time biodiversity reduction is increasingly recognized as an important environmental problem. Finding synergies and feasible solutions to these potentially conflicting objectives are likely to remain in high demand. AGRISIMU is designed for addressing these interactions and will be operationalized in full (not all components are linked yet) for this purpose. While DREMFIA and SAMA models have been implemented in mutual synergy using GAMS system (www.gams.com ), other model components have been implemented on different programming platforms. However, they can read and write spreadsheet files, which facilitates linking outputs of some models to inputs in other models, as well as using the files as intermediate results to be evaluated.

\subsection{An evolving research agenda and its prioritization in IAM-Tools project}

We conclude that for Nordic conditions AGRISIMU represents a novel and feasible approach to integrate data and output from several existing models. While sector models linking agricultural policy, economics and land use have long existed, a spatially explicit treatment of the interactions between land use and impacts on nutrient flows, and climate change has not yet been attempted.

Our main contribution is linking robust and well-tested biophysical crop and soil models for Nordic conditions to models of farm economy and for the multi-regional agricultural sector that include the important specificities for Finland. While we found that some of the basic empirical research and modelling work could be combined to considerably improve plant-soil models to capture important real world processes and, at least approximate major climate change interactions (e.g. temperature, soil moisture and $\mathrm{CO}_{2}$ ), a couple of other important processes related to climate change (overwintering, etc.) cannot yet be reproduced well and require further research.

There are many uncertain issues, such as unknown crop protection requirements for different crops and regions under changed climate. While farm level modelling can integrate many parts of the crop and animal science, and calculate optimised input use and land allocation in terms of farmers' decision making, expected shifts in future agricultural practice imposed by much more stringent environmental regulations (on agro-chemical use) will affect overall production organisation and thereby the calculation of the reliable range of product specific production costs. Especially the calculation of marginal costs of production - most relevant in sector level modelling - is challenging. This is because the production orientation and practices of Nordic agriculture, now prevalent in farm level data, has to be revised when taking into consideration climate change and other global changes. If several operations and techniques have to be changed at farm level, the overall production organisation is more or less uncertain, as well as the possibilities for input substitutions and consequent marginal costs. Furthermore, farm level dynamic land use and crop rotation decisions in the longer term have not been sufficiently modelled or analyzed. Looking at crop production and land rotation from an operations research perspective seems necessary in terms of analytical capacity and consistent interdisciplinary integration of new information and knowledge.

When moving to sector level analysis, where both demand and supply and global process of inputs and outputs are connected, the overall working of the AFS can be consistently approximated. This is because laws of markets are somewhat universal and robust. However the marginal costs from the farm level analysis forms a basis of the analysis (marginal cost pricing on competitive markets). Nevertheless the transparent combination and linking of the basic building blocks of the modelling framework provides us a major platform to study core issues of climate and global change adaptation, mitigations costs, and the use of new cultivars and adaptive management packages.

While there are many technical and computational challenges involved in operationalizing AGRISIMU for issues related to climate and other global changes in relation to AFS, here we summarize areas that require further research and receive priority in IAM-Tools: 
- To establish an empirical basis by conducting experiments, and synthesize information for important processes related to climate change (overwintering, etc.) under Nordic conditions

- To evaluate crop models for estimating regional yields under different climatic conditions and for selected administrative regions under Nordic conditions

- To develop technical coefficient generators for future-oriented production activities to provide link between field level biophysical and farm/sector-level socio-economic analyses

- To perform analysis of crop rotations, their benefits and costs as required for formulating alternative risk management options, needed to cope with farm level land management problems in the medium and long run

- To enhance the capacity of economic models to incorporate new and different input use structures and changed fertilisation response functions. Also covariance matrices of crop profitability need to be swiftly updated

These areas of research would either fill the core thematic knowledge gaps directly, or improve the model definitions and linkages, as well as calculation capacity necessary in empirical applications. Finally, resultant applications need to be carried out in close interaction with the different stakeholder groups, in order to discard production activities that are not acceptable socially, consider aspects of AFS that cannot be modelled, and get feed-back on other system properties so that AGRISIMU can evolve into a meaningful tool for decision-making support.

\section{Acknowledgements}

We are very grateful to Jyrki Aakkula for his contributions to earlier drafts, and to all members of IAM-Tools project team for their inputs. Special thanks go to Mari Walls (Syke, formerly MTT research director) for her support and council in launching the IAM-Tools initiative. We have benefited from valuable comments of two anonymous reviewers.

\section{References}

Balmann, A. (1997). Farm based modelling of regional structural change: a cellular automata approach. European Review of Agricultural Economics, 24: 85-108.

Betts, R., Sanderson, M., Hemming, D., Booth, B., Lowe, J., Jones, C., New, M. (2009). 4 degrees of global warming: regional patterns and timing. Proceedings, 4 degrees \& beyond. International Climate Conference, 28-30 September 2009, Oxford, UK. [Online] Available: http://www.eci.ox.ac.uk/4degrees/ppt/1-2betts.pdf.

Bland, W.L. (1990). Toward integrated assessment in agriculture. Agricultural Systems, 60: 157-167.

Boogaard, H.L., Van Diepen, C.A., Rötter, R.P., Cabrera, J.M.C.A., Van Laar, H.H. (1998). WOFOST 7.1. User's guide for the WOFOST 7.1 crop growth simulation model and WOFOST Control Center 1.5. 52, Wageningen.

Cox, T.L. \& Chavas, J.-P. (2001). An Interregional Analysis of Price Discrimination and Domestic Policy Reform in the U.S. Dairy Sector. American Journal of Agricultural Economics, 83: 89-106

Chavas, J-P. (1994). Production and investment decisions under sunk cost costs and temporal uncertainty. Amer. J. Agrc. Econ. 24: 76 (February), 114-127.

EC (European Commission). (2005). Impact Assessment Guidelines. European Commission, Brussles, SEC (2005) 791

Ewert, F, Van Ittersum, M.K. Bezlepkina, I., Therond, O., Andersen, E., Heckelei, T., et al. (2009). A methodology for enhanced flexibility of integrated assessment in agriculture. Environmental Science \& Policy (2009), doi: 10.1016/j.envsci.2009.02.005.

Granlund, K., Bärlund, I., Salo, T., Esala, M., Posch, M. (2007). The effect of decreasing fertilization on agricultural nitrogen leaching: a model study. Agricultural and Food Science, 16, 4: 376-386.

Hazell, P. \& Norton, R. (1986). Mathematical programming for economic analysis in agriculture. MacMillan, New york, USA. 400 p.

Helin, J. (2009). Kotieläintalouden ravinnekierron ympäristötaloudellinen optimointi - aluemalli maidon- ja viljantuotantoon erikoistuneille tiloille. In: Eila Turtola ja Kari Ylivainio (eds.). Suomen kotieläintaloudenfosforikierto - säätöpotentiaalimaatiloilla ja aluetasolla. Maa- ja elintarviketalous 138: s. 190-223. [Online] Available: http://www.mtt.fi/met/pdf/met138.pdf. 
Helin, J., Laukkanen, M., Koikkalainen, K. (2006). Abatement costs for agricultural nitrogen and phosphorus loads: a case study of crop farming in south-western Finland. Agricultural and Food Science, 15, 4: 351-374. [Online] Available: http://www.mtt.fi/afs/pdf/mtt-afs-v15n4p351.pdf

Huttunen, I., Huttunen, M., Vehviläinen, B., Tattari, S. (2007). Large scale phosphorus transport model. In: Heckrath, G.,Rubaek, G. H., Kronvang, B. (eds.). Diffuse Phosphorus Loss :Risk Assessment, Mitigation options and Ecological Effects in River Basins: The 5th International Phosphorus Workshop (IPW5), 3-7 September 2007 in Silkeborg, Denmark. Aarhus Universitet, Faculty of Plant Science. P. 215-217. DJF Plant Science; 130. ISBN87-91949-20-3. [Online] Available: http://www.agrsci.dk/var/agrsci/storage/original/application/115f2ba 148 1b6a113288c6f9a773d572.

IMAGE team. (2001). The IMAGE 2.2 implementation of the SRES scenarios: a comprehensive analysis of emissions, climate change and impacts in the $21^{\text {st }}$ century. RIVM, Bilthoven, RIVM CD-ROM Publication no. 481508018.

Janssen, S., Van Ittersum, M.K. (2007). Assessing farm innovations and responses to policies: a review of bio-economic farm models. Agricultural Systems, 94, 622-636.

Jansson, P., Karlberg, L. (2004). COUP manual. Coupled heat and mass transfer model for soil-plant-atmosphere systems. Stockholm, Sweden.

Just, R. (2003). Risk research in agricultural economics: opportunities and challenges for the next twenty-five years. Agricultural Systems, 75: 123-159.

Laborte, A., Van Ittersum, M.K., Van den Berg, M.M. (2007). Multi-scale analysis of agricultural development : a modelling approach for Ilocos Norte, Philippines. Agricultural Systems, 94: 862-873.

Lapvetelainen, T., Regina, K., Perälä, P. (2007). Peat-based emissions in Finland's national greenhouse gas inventory. Boreal Environ.Res., 12, 225-236.

Lehtonen, H. (2001). Principles, structure and application of dynamic regional sector model of Finnish agriculture. Academic dissertation. Systems Analysis Laboratory, Helsinki University of Technology. Publications 98. Agrifood Research Finland, Economic Research (MTTL). Helsinki. 265 p.

Lehtonen, H., Peltola, J., Sinkkonen, M. (2006). Co-effects of climate policy and agricultural policy on regional agricultural viability in Finland. Agricultural Systems, 88: 472-493.

Lehtonen, H. \& Kujala, S. (2007). Climate change impacts on crop risks and agricultural production in Finland. Contributed paper presented in 101st EAAE seminar "Managing Climate Risks in Agriculture", held in Berlin, Germany, July 5-6 2007. 21 p. [Online] Available: http://ageconsearch.umn.edu/bitstream/9259/1/sp07le01.pdf.

MTT. (2009). www.mtt.fi - IAM-Tools project webpage by MTT Agrifood Research Finland, Jokioinen, Finland.

Pathak, H., Wassmann, R. ( 2007). Introducing greenhouse gas mitigation as a development objective in rice-based agriculture: I. Generation of technical coefficients. Agricultural Systems, 94(3): 821-30.

Ponsioen, T., Hengsdijk, H., Wolf, J. et al. (2006). TechnoGIN, a tool for exploring and evaluating resource use efficiency of cropping systems in East and Southeast Asia. Agricultural Systems, 87: 80-100.

Rankinen, K., Salo, T., Granlund, K. \& Rita, H. (2007). Simulated nitrogen leaching, nitrogen mass field balances and their correlation on four farms in south-western Finland during the period 2000 2005. Agricultural and Food Science, 16, 4: 387-406.

Regina, K., Lehtonen, H., Nousiainen, J. \& Esala, M. (2009). Modelled impacts of mitigation measures on greenhouse gas emissions from Finnish agriculture up to 2020. Forthcoming in Agricultural and Food Science, Vol. 18, No 4.

Rötter, R.P., Hoanh, C.T., Laborte, A.G. et al. (2005). Integration of Systems Network (SysNet) tools for regional land use scenario analysis in Asia. Environmental Modelling and Software, 20(3), 291-307.

Rötter, R., Lehtonen, H., Aakkula, J. et al. (2008). A framework for integrated assessment modelling of agricultural systems. MTT Agrifood Research Finland (working document), $22 \mathrm{p}$.

Rötter, R.P., Palosuo, T., Salo, T. et al. (2009). What would happen to barley production in Finland if the global temperature increases above $4 \mathrm{oC}$. Proceedings, 4 degrees \& beyond. International Climate Conference, 28-30 September 2009, Oxford, UK. 
Salo, T. (1996). Simulated and measured nitrogen status in soil and in onion crop. Acta Horticulturae, 428: p. 193-204.

Soete, L. \& Turner, R. (1984). Technology diffusion and the rate of technical change. The Economic Journal, 94: 612-623.

Supit, I., Hooijer, A.A., van Diepen, C.A., eds. (1994). Ssystem description of the WOFOST6.0crop simulation model implemented in CGMS. Vol.1: Theory and Algorithms. Joint Rsearch Centre, Ispra, Italy.

Takayama, T. \& Judge G.G. (1971). Spatial and Temporal Price and Allocation Models. North-Holland Publishing Company.

Van Ittersum, M.K., Leffelaar, P.A., van Keulen, H., Kropff, M.J., Bastiaans, L., Goudriaan, J. (2003). On approaches and applications of the Wageningen crop models. Eur.J.Agron., 18, 201-234.

Van Ittersum, M.K., Rötter, R.P., Van Keulen H. et al. (2004). A systems network approach (SysNet) for interactively evaluating strategic land use options at sub-national scale in South and South-east Asia. Land Use Policy 21: 101-113.

Van Ittersum, M.K., Ewert, F., Heckelei, T., Wery, J., Alkan Olsson, J., et al. (2008). Integrated assessment of agricultural systems - A component-based framework for the European Union (SEAMLESS). Agricultural Systems, 96, 150-165.

Van Tongeren, F., Van Meijl, H., Surry, Y. (2001). Global models applied to agricultural and trade policies: a review and assessment. Agricultural Economics, 26 (2), 149-172.

Wade, A., Durand, P., Beaujoan, V., Wessels, W., Raat, K., Whitehead, P.G., Butterfield, D., Rankinen, K. and Lepistö, A. (2002). Towards a generic nitrogen model of European ecosystems New model structure and equations. Hydrology and Earth System Sciences, 6, 559-582.

Yli-Halla M., Tattari S., Bärlund I., Tuhkanen H.-R., Posch M.,Siimes K. and Rekolainen S. (2005). Simulating processes of soil phosphorus in geologically young acidic soils in Finland. Transactions of the ASAE, 48(1): 101-108.

Table 1. Component models included in the Finnish Integrated Modelling Framework for agrifood systems analysis. The input and output codes (such as OUT1-DREMFIA) show which outputs are used as inputs in other models in integrated analysis (Note, that this table only contains the core model components; output from other expert systems will be utilized as required by the specific question under consideration)

\begin{tabular}{|c|c|c|}
\hline Model & Input & Output \\
\hline $\begin{array}{c}\text { DREMFIA } \\
\text { a dynamic regional sector model } \\
\text { of Finnish Agriculture }\end{array}$ & $\begin{array}{ll}\text { - } & \text { nitrogen response functions for } \\
\text { crop yields (OUT1-COUP) } \\
\text { - } \\
\text { milk and meat yield response } \\
\text { functions } \\
\text { - } \\
\text { EU (global) changes in input and } \\
\text { output prices } \\
-\quad \text { agricultural + env. policies } \\
-\quad \text { soil data }\end{array}$ & $\begin{array}{ll}- & \text { land use at regional level } \\
& \text { (OUT1-DREMFIA) } \\
- & \text { fertilisation } \\
& \text { (OUT2-DREMFIA) } \\
-\quad & \text { feed diets of animals } \\
-\quad & \text { number of animals } \\
& \text { regionally } \\
-\quad & \text { food demand, } \\
& \text { exports,imports } \\
-\quad & \text { domestic commodity prices } \\
& \text { (OUT3-DREMFIA) } \\
\end{array}$ \\
\hline $\begin{array}{c}\text { SAMA } \\
\text { Static Agent Model of Agriculture } \\
\text { developed for several farm types } \\
\text { in Finland }\end{array}$ & $\begin{array}{ll}\text { - } & \text { nitrogen response functions for } \\
\text { crop yields (OUT1-WOFOST) } \\
-\quad \text { milk and meat yield response } \\
\text { functions } \\
\text { - } \\
\text { input and output prices }\end{array}$ & $\begin{array}{ll}\text { - } & \text { land use at farm level } \\
& \text { (up-scalable to watershed } \\
& \text { level) (OUT1-SAMA) } \\
\text { - } & \text { fertilisation (OUT2-SAMA) } \\
\text { - } & \text { feed diets of animals }\end{array}$ \\
\hline
\end{tabular}




\begin{tabular}{|c|c|c|}
\hline & $\begin{array}{ll} & \text { (OUT3-DREMFIA }) \\
- & \text { agricultural + env. policies } \\
- & \text { soil and topographical data } \\
- & \text { average erosion, runoff and } \\
& \text { nitrogen load for land types } \\
& \text { (OUT1-2-COUP, } \\
\text { OUT1-2-ICECREAM) }\end{array}$ & $\begin{array}{ll}- & \text { number of animals } \\
- & \text { yields } \\
- & \text { tillage (OUT3-SAMA) } \\
- & \text { farm profit } \\
- & \text { erosion and runoff } \\
- & \text { nitrogen \& phosphorus loads } \\
- & \text { GHG emissions }\end{array}$ \\
\hline $\begin{array}{c}\text { COUP } \\
\text { A model for } \\
\text { soil-plant-atmosphere systems }\end{array}$ & $\begin{array}{ll}\text { - } & \text { weather data } \\
\text { - } & \text { soil data } \\
\text { - } & \text { crop data } \\
\text { - } & \text { soil management data }\end{array}$ & $\begin{array}{ll}- & \text { soil water balances } \\
- & \text { nitrogen cycle including } \\
& \text { losses by leaching and } \\
& \text { denitrification } \\
& \text { (OUT1-COUP) } \\
- & \text { carbon cycle and change in } \\
& \text { soil carbon stocks } \\
\text { (OUT2-COUP) }\end{array}$ \\
\hline $\begin{array}{l}\text { WOFOST } \\
\text { A dynamic crop growth } \\
\text { simulation model }\end{array}$ & $\begin{array}{ll}\text { - } & \text { weather data } \\
\text { - } & \text { soil data } \\
\text { - } & \text { basic crop/cultivar data } \\
\text { - } & \text { agricultural practices }\end{array}$ & 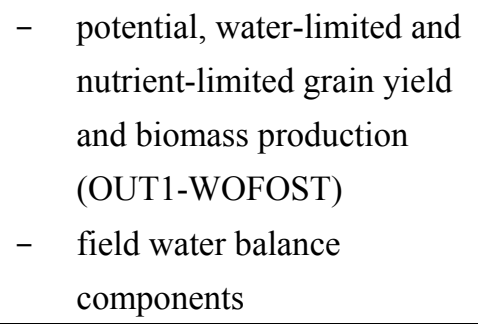 \\
\hline $\begin{array}{c}\text { INCA-N } \\
\text { an integrated nitrogen model for } \\
\text { multiple source assessment in } \\
\text { catchments }\end{array}$ & $\begin{array}{ll}\text { - } & \text { weather data } \\
\text { - } & \text { land use } \\
& \text { (OUT1-2-DREMFIA/OUT1-2-SA } \\
\text { MA) } \\
\text { - } \quad \text { soil and topographical data } \\
-\quad \text { agricultural practices } \\
\text { (OUT3-SAMA) }\end{array}$ & $\begin{array}{l}\text { - daily estimates of discharge, } \\
\text { stream water } \mathrm{N} \\
\text { concentrations and } \mathrm{N} \text { fluxes }\end{array}$ \\
\hline $\begin{array}{c}\text { WSFS-P } \\
\text { a hydrological rainfall-runoff } \\
\text { model }\end{array}$ & $\begin{array}{l}\text { - } \text { weather data } \\
\text { - land use } \\
\text { (OUT1-2-DREMFIA/OUT1-2-SA } \\
\text { MA) }\end{array}$ & $\begin{array}{l}\text { - } \quad \text { hydrological cycle of whole } \\
\text { Finland } \\
\text { - } \quad \text { P transport }\end{array}$ \\
\hline $\begin{array}{c}\text { ICECREAM } \\
\text { a field-scale nutrient transport } \\
\text { model }\end{array}$ & $\begin{array}{ll}\text { - } & \text { weather data } \\
\text { - } & \text { land use } \\
\text { (OUT1-2-DREMFIA/OUT1-SAM } \\
\text { A) } \\
\text { - } \quad \text { soil and topographical data } \\
\text { - } \quad \text { crop data } \\
\text { - } \quad \text { soil management (OUT3-SAMA) }\end{array}$ & $\begin{array}{ll}- & \text { soil water balance } \\
- & \text { soil erosion } \\
& \text { (OUT1-ICECREAM) } \\
- & \text { N and P transport } \\
& \text { (OUT2-ICECREAM) }\end{array}$ \\
\hline
\end{tabular}




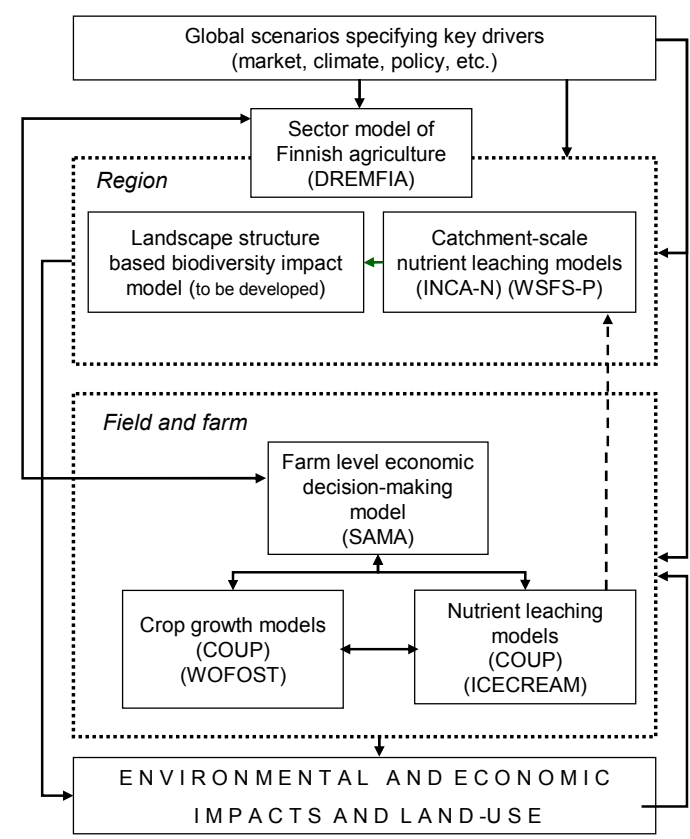

Figure 1. The integrated modelling framework AGRISIMU

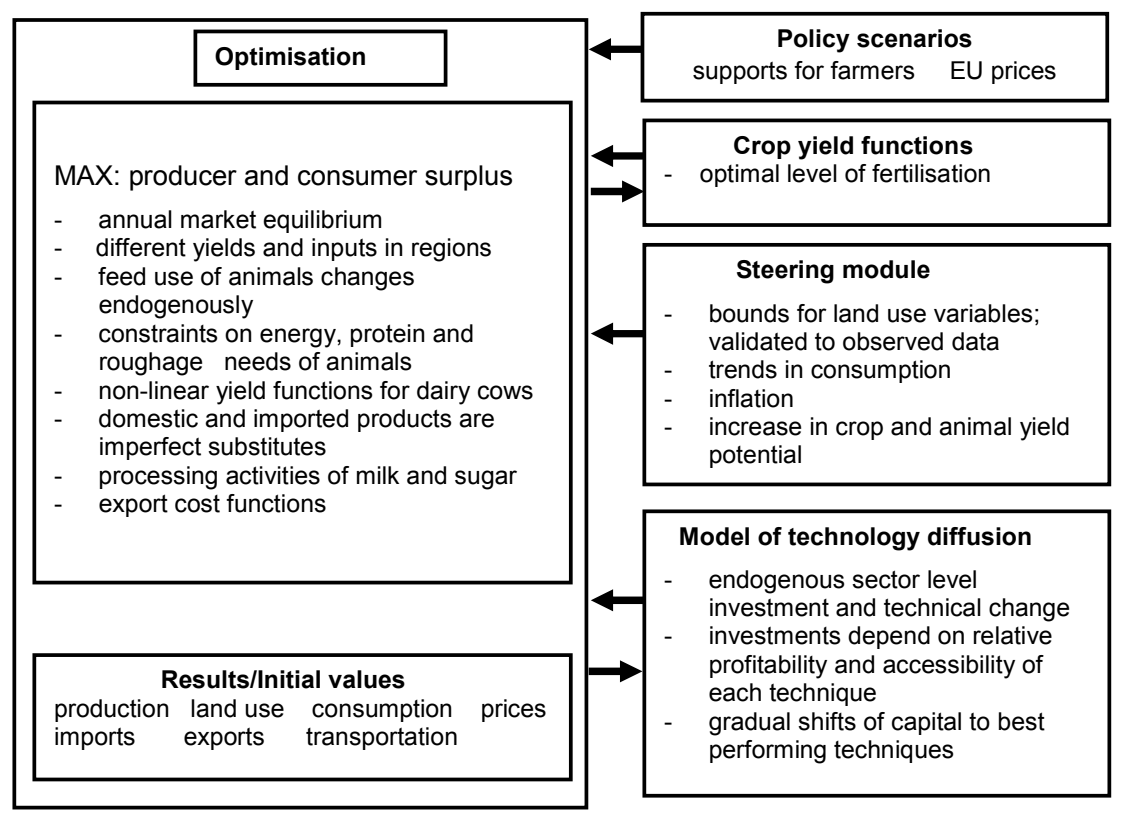

Figure 2. Basic structure of DREMFIA sector model 